Summary This study compared the quantitative influence of a variety of factors on the performance of low-beam headlamps. The factors included were vertical aim, horizontal aim, mounting height, lateral separation, lens dirt, lamp voltage, number of functioning lamps, vehicle type, beam pattern and light source. The following aspects of headlamp performance were considered: visibility of pedestrians, visibility of road delineation, visibility of vehicle reflex reflectors, visibility of retroreflective traffic signs, visibility of targets near the road expansion point, glare directed towards oncoming drivers, glare reflected from wet pavenent towards oncoming drivers, glare directed towrards rearview mirrors of preceding vehicles, and foneground illumination. A sales-weighted average US beam pattern, with lamps mounted at sales-weighred average locations, formed the basis for most of the analyses. The results indicate that, from among the factors studied, vertical aim is overwhelmingly the most important factor in influencing the performance of low-beam beadlamps. The second most important factor is the number of functioning lamps. The main implication of this study is that major improvements in current (fixed as opposed to adaptive) low-beam headlighting could be achieved primarily by better control of vertical aim and by use of longer-life headlamps.

\title{
Quantitative comparisons of factors influencing the performance of low-beam headlamps
}

\author{
M Sivak PhD, M J Flannagan PhD and T Miyokawa \\ The University of Michigan Transportation Research Institure, 2901 Baxter Road, Ann Arbor, Michigan 48109-2150, USA
}

Received 3 June 1999, in final form 7 February 2000

\section{Introduction}

The overall photometric performance of low-beam headlamps is determined by a variety of factors. Some of these factors are under the control of the designer of the lamp (e.g. the light source chosen), the vehicle manufacturer (e.g. lamp mounting height) or the driver (e.g. cleanliness of the lamp lenses). Still other factors are outside anyone's direct control (e.g. pavement wetness).

Past studies have investigated the effects of many relevant factors. However, these studies have used a variety of methods to evaluate the importance of the factors in question. Consequently, cross-study comparisons are often difficult. For example, it is difficult to compare the effects of headlamp misaim on pedestrian detection distances derived from computer models ${ }^{(1)}$ with the effects of lens dirt on light output ${ }^{(2)}$.

One notable exception to using different methodologies to evaluate the influence of different factors was a study by Perel ${ }^{(3)}$. This study used the same methodology (the chess mode $\left.{ }^{(4)}\right)$ to compare the effects of several headlamp factors (including overall intensity, aim, mounting height and beam pattern) on three performance parameters (pedestrian detection, delineation detection and discomfort glare). The results were presented in terms of the degree of sensitivity of the performance measures to the headlamp factors (low, moderate and high). Perel found that 'only small performance increases could be achieved by beam pattern modifications, improved aim, and increased overall intensity' (p. 225). However, Perel concluded that the method used (the cHEss model) might not be sensitive enough for the task at hand. According to Perel, 'part of the difficulty in identifying performance improvements was found to be the low sensitivity of the cHEss figure of merit to changes in beam photometrics' (p. 225).

The present study was designed to evaluate the effects of a variety of factors on the effective photometric performance of low-beam headlamps using the same methodology. The effective photometric performance was measured by the actual luminous intensity directed to several important points in space relative to the lamp (e.g. a pedestrian on the right shoulder at a distance of $100 \mathrm{~m}$, and an oncoming driver's eyes in the adjacent lane at $50 \mathrm{~m}$ ). The goal was to provide (for each important point in space) rank ordering of the importance of the factors in question, and thereby to identify the most effective means of improving current fixed headlighting. Adaptive headlighting (headlighting that varies dynamically with conditions such as speed, road curvature and weather) was not considered.

Although, conceptually, the present study was similar to that of Perel ${ }^{(3)}$, there are three major differences between these two studies. First, we examined a wider range of factors that could affect headlamp performance. Second, we considered more aspects of headlamp performance. Third, instead of using specific beam patterns, we used a sales-weighted average beam pattern from current US vehicles ${ }^{(5)}$.

\section{Method}

\subsection{Approach}

The approach was as follows:

(1) Use a representative US low-beam pattern, with lamps mounted in representative positions, to quantify the effects of factors in (2) on the performance aspects in (3).

(2) Select a set of factors whose effects on the beam pattern are generally considered to be of importance.

(3) Select a set of points in space that represent major performance aspects of the beam pattern.

The effects of factors in (2) were quantified by calculating the percentage change in luminous intensity directed from both lamps towards the points in space in (3). As an example, assume that the luminous intensities from the representative low-beam pattern directed towards a relevant point in space (e.g. the eyes of an oncoming driver) were $600 \mathrm{~cd}$ from the left lamp and $400 \mathrm{~cd}$ from the right lamp. Thus the combined luminous intensity from the two lamps was $1000 \mathrm{~cd}$. Furthermore, let us assume that because of the factor in 
question (e.g, scatter from lens dirt), the combined luminous intensity directed to the same point in space has changed to $1200 \mathrm{~cd}$. Thus, for this example, the examined factor would result in a $20 \%$ increase in combined luminous intensity.

\subsection{Representative US low-beam pattern and lamp positions}

We used the sales-weighted data from Sivak, Flannagan, Kojima and Traube ${ }^{(5)}$. That study photometered 35 low beams that were manufactured for use on $45 \%$ of all cars, light trucks and vans sold in the USA for model year 1997. The photometric information for each lamp was weighted by the 1997 sales figures for the corresponding vehicle. For the basic photometry data for the present study, we used the salesweighted median data for cars only. The data extend from $45^{\circ}$ left to $45^{\circ}$ right, and from $5^{\circ}$ down to $7^{\circ}$ up (all in $0.5^{\circ}$ steps).

Except as noted below, in all of the analyses we used representative headlamp mounting positions. Specifically, we used a mounting height of $0.62 \mathrm{~m}$ and a lamp separation of $1.12 \mathrm{~m}$. These values are the sales-weighted means from a recent survey of headlamps on cars in the USA (). We used the same beam pattern for both the left and the right lamps. (Sivak et $a l .{ }^{(7)}$ found that left lamps and right lamps that were manufactured for the same vehicle were photometrically very similar.)

\subsection{Factors}

The following factors were considered: vertical aim, horizontal aim, mounting height, lateral separation (including a comparison of two lamps located in the same position versus lamps laterally separated), lens dirt, larnp voltage, number of functioning lamps, vehicle type, beam pattern and lightsource type.

Vertical aim. A recent US survey of headlamp aim in 768 inservice cars, vans and light trucks ${ }^{(8)}$ found that the mean vertical aim was close to $0^{\circ}$ with a standard deviation of $0.65^{\circ}$. The measurements were taken with the drivers, passengers (if any), and luggage (if any) in the positions they were in when arriving at the test sites. We investigated the effects of \pm 2 standard deviations from the mean $-1.3^{\circ}$ up and $1.3^{\circ}$ down. (The range of \pm 2 standard deviations is expected to cover $95 \%$ of all aims.)

Horizontal aim. Copenhaver and Jones ${ }^{(8)}$ found the mean horizontal aim to be about $0.2^{\circ}$ left with a standard deviation of $0.55^{\circ}$. Again following the logic of using \pm 2 standard deviations from the mean, we considered $1.3^{\circ}$ left and $0.9^{\circ}$ right.

Mounting height. As indicated above, a recent study (p) found the sales-weighted mean headlamp mounting height for cars to be $0.62 \mathrm{~m}$, with a standard deviation of $0.02 \mathrm{~m}$. Thus, when examining the effects of mounting height, we considered $0.58 \mathrm{~m}$ and $0.66 \mathrm{~m}$ ( \pm 2 standard deviations from the mean).

Lateral separation. Sivak et al (9) $^{(0)}$ ond the sales-weighted mean lateral separation berween low-beam headlamps to be $1.12 \mathrm{~m}$, with a standard deviation of $0.12 \mathrm{~m}$. Thus, when examining the effects of lamp separation, we considered $1.36 \mathrm{~m}$ and $0.88 \mathrm{~m}$ ( \pm 2 standard deviations from the mean). Furthermore, we also included lamp separation of $0 \mathrm{~m}$, corresponding to simulations that use the same (cyclopean) location for both lamps.

Lens dirt. Sivak et ale evaluated changes in the light ourput of low-beam headlamps as a function of dirt accumulated during a $482-\mathrm{km}$ route, representing a 10 -day amount of driving for a typical US driver. The complete route was traversed on three separate occasions, under each of the following environmental conditions: summer while dry, summer while wet, and winter with road salt. Luminous-intensity matrices were obtained for a rectangular central portion of the beam, extending from $20^{\circ}$ left to $20^{\circ}$ right, and from $5^{\circ}$ down to $5^{\circ}$ up. The results showed that linear regressions provided good fits for the relationship between 'clean' and 'dirty' luminous intensities. We selected the most extreme situation tested by Sivak et al(2) (winter with road salt) and used the corresponding regression equation (dirty luminous intensity $=0.72 \times$ clean luminous intensity +112 ).

Lamp voltage. Sivak, Flannagan, Traube and Miyokawa ${ }^{7}$ ) found that voltage changes between $12.0 \mathrm{~V}$ and $13.5 \mathrm{~V}$ caused light ourput to change by the same proportion throughout the beam partem. Therefore, for filament lamps, it is reasonable to use a single constant for all values in a beam pattern when converting photometry at one voltage to photometry at a different voltage. Furthermore, the obtained constants were in good agreement with the constants derived using the standard IESNA formula ${ }^{(9)}$. In this analysis, we used the change from $12.8 \mathrm{~V}$ to $12.0 \mathrm{~V}$ (with a resulting decrease in luminous intensity of $20 \%$ ) and the change from $12.8 \mathrm{~V}$ to $13.5 \mathrm{~V}$ (with a resulting increase in luminous intensity of $20 \%$ ).

Number of functioning lamps. Here we evaluated the effects of having either only the left or only the right lamp functioning, as compared with having both lamps functioning. A recent US survey of 102000 moving vehicles found that $2.3 \%$ had one headlamp not functioning ${ }^{(10)}$.

Vehicle type. As indicated above, all of the previous analyses used the sales-weighted median beam pattern for cars from Sivak et $a{ }^{(5)}$, while assuming a lamp mounting height of $0.62 \mathrm{~m}$ and a lamp separation of $1.12 \mathrm{~m}$. In these analyses, we compared the effect of changing from the sales-weighted photometric data for cars to the sales-weighted photometric data for light trucks and vans (also from Sivak et al.(5)). Importantly, the lamps on light trucks and vans were assumed to be mounted at $0.83 \mathrm{~m}$, with a lateral separation of $1.30 \mathrm{~m}$. (The locations of headlamps both for cars and for light trucks and vans were based on the sales-weighted data from Sivak et $a^{\left({ }^{(6)}\right.}$.)

Beam pattern. Sivak, Flannagan and Sato ${ }^{(1)}$ provided detailed photometry information on 37 lamps manufactured for sale in Europe. We used the median data (which were not salesweighted) from that study and the sales-weighted US median data from Sivak et al ${ }^{(5)}$ to compare the effects of changing from the US to the European beam pattern. The European lamps were assumed to be positioned at the same mounting height and lateral separation as the US lamps.

Light-source type. In addition to the aggregate information, Sivak et al (5) also provide photometric data broken down by light source. We used the data from that study to compare a light source without an internal shield (9007) with a light source with an internal shield (H4). Each light source created a beam pattern designed to meet the current US specifications.

\subsection{Major performance aspects of low-beam headlamps}

The following performance aspects were considered: visibiliry of pedestrians, visibility of road delineation, visibility of reflex reflectors, visibility of retroreflective traffic signs, visibility of targets near the road expansion point, glare directed towards oncoming drivers, glare reflected from wet pavement towards oncoming drivers, glare directed towards rearview mirrors of preceding vehicles, and foreground illumination. For each of the performance aspects, a typical geometric situation was specified in terms of the longitudinal, lateral and vertical 
positions (see Table 1), and the corresponding visual angles from each of the two lamps were calculated (see Table 2).

Visibility of pedestrians. Pedestrians walking on the right edge line and on the left edge line of the left adjacent lane were considered. In these and all subsequent analyses the lane width was set at $3.7 \mathrm{~m}$. Two distances were included: $100 \mathrm{~m}$ and $50 \mathrm{~m}$ (assuming two different approaching speeds). Feet were selected as the relevant location on the pedestrians (i.e. vertical position was set at $0 \mathrm{~m}$ above the roadway).

Visibility of road delineation. Two distances were selected for road delineation: $100 \mathrm{~m}$ and $50 \mathrm{~m}$. Both the right edge line and the left edge line of the adjacent lane were included. (An alert reader will notice that the delineation locations and pedestrian locations were identical.)

Visibility of reflex reflectors on the rear of vehicles. Two sets of mounting-height locations were considered: $0.5 \mathrm{~m}$ and $1.0 \mathrm{~m}$.
Both left and right reflectors were included, at a separation of $1.2 \mathrm{~m}$. The mounting heights chosen approximately represent the range found in an informal survey of 61 cars, light trucks and vans belonging to the staff of our Institute. The separation chosen corresponds to the mean value from that survey.

$V$ isibility of retroreflective traffic signs. Three locations of retroreflective traffic signs were included: right shoulder-mounted, centre overhead, and left shoulder-mounted-all at $150 \mathrm{~m}$.

$V$ isibility of targets near the road expansion point. The longitudinal distance here is infinity, the lateral offset is zero, and the vertical height is the same as that of the lamps. (For practical purposes, the lateral and vertical locations are arbitrary.)

Glare directed towards oncoming drivers. The oncoming driver was assumed to be in the left adjacent lane at a distance of $50 \mathrm{~m}$. The oncoming driver's eye location was selected on the basis of the sales-weighted data in Sivak et al..$^{(6)}$.

Table 1 Positions of representative locations of the performance aspects, where $x$ is the longitudinal distance from the headlamps, $y$ is the lateral distance from the vehicle centreline, and $z$ is the vertical distance from the ground. (All distances are in metres)

\begin{tabular}{|c|c|c|c|}
\hline Performance aspect & $x$ & $y$ & $z$ \\
\hline Visibility of a right pedestrian and road delineation at $100 \mathrm{~m}$ & 100 & 1.85 & 0 \\
\hline Visibility of a righr pedestrian and road delinearion at $50 \mathrm{~m}$ & 50 & 1.85 & 0 \\
\hline Visibility of a left pedestrian and road delineation at $100 \mathrm{~m}$ & 100 & -5.55 & 0 \\
\hline Visibility of a left pedestrian and road delineation at $50 \mathrm{~m}$ & 50 & -5.55 & 0 \\
\hline Visibility of a right rear reflex reflector at $20 \mathrm{~m}$; mounting height $0.5 \mathrm{~m}$ & 20 & 0.60 & 0.50 \\
\hline Visibility of a right rear reflex reflector at $20 \mathrm{~m}$; mounting height $1.0 \mathrm{~m}$ & 20 & 0.60 & 1.00 \\
\hline Visibility of a left rear reflex reflector at $20 \mathrm{~m}$; mounting height $0.5 \mathrm{~m}$ & 20 & -0.60 & 0.50 \\
\hline Visibility of a left rear reflex reflector at $20 \mathrm{~m}$; mounting height $1.0 \mathrm{~m}$ & 20 & -0.60 & 1.00 \\
\hline Visibility of a retroreflective traffic sign; right shoulder at $150 \mathrm{~m}$ & 150 & 6.15 & 2.10 \\
\hline Visibility of a retroreflective traffic sign; centre overhead at $150 \mathrm{~m}$ & 150 & 0 & 6.10 \\
\hline Visibiliry of a retroreflective traffic sign; left shoulder at $150 \mathrm{~m}$ & 150 & -9.85 & 2.10 \\
\hline Visibility of a targer near the road expansion point & $\infty$ & 0 & 0.62 \\
\hline Glare directed towards an oncoming driver at $50 \mathrm{~m}$ & 50 & -3.35 & 1.11 \\
\hline Glare reflected from wet pavement towards an oncoming driver at $50 \mathrm{~m}$ & 17.9 & -1.20 & 0 \\
\hline Glare directed towards a left mirror in the right adjacent lane at $20 \mathrm{~m}$ & 20 & 2.83 & 0.98 \\
\hline Glare directed towards a centre mirror in the same lane at $20 \mathrm{~m}$ & 20 & 0 & 1.24 \\
\hline Glare direcred towards a right mirror in the left adjacent lane as $20 \mathrm{~m}$ & 20 & -2.83 & 0.98 \\
\hline Foreground illurnination at $15 \mathrm{~m}$ & 15 & 0 & 0 \\
\hline Foreground illumination at $25 \mathrm{~m}$ & 25 & 0 & 0 \\
\hline
\end{tabular}

Table 2 Angles (in degrees) of the representative locations for the performance aspects, with respect to each of the two headlamps. $(L=$ left, $R=$ right, $D=$ down, $U=$ up)

\begin{tabular}{lll}
\hline Performance aspect & Left lamp & Right lamp \\
\hline Visibility of a right pedestrian and road delineation at $100 \mathrm{~m}$ & $1.4 \mathrm{R}, 0.4 \mathrm{D}$ & $0.7 \mathrm{R}, 0.4 \mathrm{D}$ \\
Visibility of a right pedestrian and road delineation at $50 \mathrm{~m}$ & $2.8 \mathrm{R}, 0.7 \mathrm{D}$ & $1.5 \mathrm{R}, 0.7 \mathrm{D}$ \\
Visibility of a left pedestrian and road delineation at $100 \mathrm{~m}$ & $2.9 \mathrm{~L}, 0.4 \mathrm{D}$ & $3.5 \mathrm{~L}, 0.4 \mathrm{D}$ \\
Visibility of a left pedestrian and most delineation at $50 \mathrm{~m}$ & $5.7 \mathrm{~L}, 0.7 \mathrm{D}$ & $7,0 \mathrm{~L}, 0.7 \mathrm{D}$ \\
Visibilicy of a right rear reflex reflector at $20 \mathrm{~m}$; mounting height $0.5 \mathrm{~m}$ & $3.3 \mathrm{R}, 0.3 \mathrm{D}$ & $0.1 \mathrm{R}, 0.3 \mathrm{D}$ \\
Visibility of a right rear reflex reflector at $20 \mathrm{~m}$; mounting height $1.0 \mathrm{~m}$ & $3.3 \mathrm{R}, 1.1 \mathrm{U}$ & $0.1 \mathrm{R}, 1.1 \mathrm{U}$ \\
Visibility of a left rear reflex reflector at $20 \mathrm{~m}$; mounting height $0.5 \mathrm{~m}$ & $0.1 \mathrm{~L}, 0.3 \mathrm{D}$ & $3.3 \mathrm{~L}, 0.3 \mathrm{D}$ \\
Visibility af a left rear reflex reflector at $20 \mathrm{~m}$; mounting height $1.0 \mathrm{~m}$ & $0.1 \mathrm{~L}, 1.1 \mathrm{U}$ & $3.3 \mathrm{~L}, 1.1 \mathrm{U}$ \\
Visibility of a retroreflective traffic sign; right shoulder at $150 \mathrm{~m}$ & $2.6 \mathrm{R}, 0.6 \mathrm{U}$ & $2.1 \mathrm{R}, 0.6 \mathrm{U}$ \\
Visibility of a retroreflective traffic sign; centre overhead at $150 \mathrm{~m}$ & $0.2 \mathrm{R}, 2.1 \mathrm{U}$ & $0.2 \mathrm{~L}, 2.1 \mathrm{U}$ \\
Visibility of a retroreflective traffic sign; left shoulder at $150 \mathrm{~m}$ & $3.5 \mathrm{~L}, 0.6 \mathrm{U}$ & $4.0 \mathrm{~L}, 0.6 \mathrm{U}$ \\
Visibility of a target near the road expansion point & 0,0 & 0,0 \\
Glare directed towards an oncoming driver at $50 \mathrm{~m}$ & $3.2 \mathrm{~L}, 0.6 \mathrm{U}$ & $4.5 \mathrm{~L}, 0.6 \mathrm{U}$ \\
Glare reflected from wet pavement towards an oncoming driver at $50 \mathrm{~m}$ & $3.2 \mathrm{~L}, 2.0 \mathrm{D}$ & $4.5 \mathrm{~L}, 2.0 \mathrm{D}$ \\
Glare directed towards a left mirror in the right adjacent lane at $20 \mathrm{~m}$ & $9.6 \mathrm{R}, 1.0 \mathrm{U}$ & $6.5 \mathrm{R}, 1.0 \mathrm{U}$ \\
Glare directed towards a centre mirror in the same lane at $20 \mathrm{~m}$ & $1.6 \mathrm{R}, 1.8 \mathrm{U}$ & $1.6 \mathrm{~L}, 1.8 \mathrm{U}$ \\
Glare directed towards a right mirror in the left adjacent lane at $20 \mathrm{~m}$ & $6.5 \mathrm{~L}, 1.0 \mathrm{U}$ & $9.6 \mathrm{~L}, 1.0 \mathrm{U}$ \\
Foreground illumination at $15 \mathrm{~m}$ & $2.1 \mathrm{R}, 2.4 \mathrm{D}$ & $2.1 \mathrm{~L}, 2.4 \mathrm{D}$ \\
Foreground illumination at $25 \mathrm{~m}$ & $1.3 \mathrm{R}, 1.4 \mathrm{D}$ & $1.3 \mathrm{~L}, 1.4 \mathrm{D}$
\end{tabular}


Glare reflected from wet pavement towards oncoming drivers. The oncoming driver was, again, assumed to be in the left adjacent lane at a distance of $50 \mathrm{~m}$. The corresponding location on the pavement was calculated by assuming that the angle of reflection is equal to the angle of incidence.

Glare directed towards reariew mirrors of preceding cars. All three mirrors were considered. For the centre mirror, the preceding car was in the same lane. For the left mirror, the preceding car was in the right adjacent lane, while for the right mirror it was in the left adjacent lane. The distance between the headlamps and the mirrors was set at $20 \mathrm{~m}$. The mounting position of the mirrors was based on a late-model passenger car.

Foreground illumination. Two locations were used: pavement $15 \mathrm{~m}$ and $25 \mathrm{~m}$ ahead (both at the centreline of the vehicle).

\subsection{Simplifying assumptions concerning retroreflective materials}

This study investigated the changes in the combined luminous intensities from both lamps that were directed towards certain points in space. An explicit assumption was made that a given amount of luminous intensity is equally effective whether it originates from the left lamp or the right lamp. This assumption is valid for diffusely reflecting materials. However, because the driver is not seated at the centreline of the vehicle, this assumption is not strictly correct when dealing with retroreflective materials (e.g. retroreflective traffic signs or vehicle reflex reflectors). Because of the offset of the driver towards the left side of the vehicle (for the righthand traffic), the observation angle (the angle between the headlamp, the retroreflective material, and the driver eye point) is smaller for the left lamp than for the right lamp. Consequently, a given luminous intensity directed towards retroreflective objects is more effective if it originates from the left lamp than from the right lamp, because more light will be reflected back to the driver's eyes from the incident illumination that originated from the left lamp.

The observation angle is affected by several of our factors, such as lamp separation, lamp mounting height and vehicle type. (Vehicle-type manipulation involved changes in both lamp location and driver eye point location.) Again, the effects of the changes in observation angle were not included in the calculations.

\section{Results}

The results are presented in Tables 3 to 8 in terms of the percentage changes in luminous intensity directed towards the points in space representing the important performance aspects of headlamps.

\section{Discussion}

\subsection{Sensitivity of the headlamp performance aspects}

Visibility of pedestrians and delineation (Table 3). The light directed towards the pedestrians and road delineation was most influenced by vertical aim. The changes in luminous intensity due to vertical misaim exceeded $100 \%$ for the leftside targets, and were just below $100 \%$ for the right-side targets. Number of functioning lamps was the second most important factor, with the changes hovering around $50 \%$. The third most important factor was beam pattern.

Visibility of reflex reflectors on the rear of oehicles (Table 4). Vertical aim was, by far, the most important factor. The changes in the incident illumination on the reflectors mounted at height of $1.0 \mathrm{~m}$ were $835 \%$ and $670 \%$ (for the right and left reflectors, respectively). The analogous changes for the reflectors at $0.5 \mathrm{~m}$ were $69 \%$ and $131 \%$. Vehicle type (cars versus light trucks and vans) was the second most important factor, with the effects for the four conditions of interest ranging between $60 \%$ and $115 \%$. Presumably, the influence of vehicle type was primarily due to the differences in lamp mounting height $(0.62 \mathrm{~m}$ versus $0.83 \mathrm{~m})$. The third most important factor was number of functioning lamps. (Notably, the amount of incident light was about 10 times greater at a mounting height of $0.5 \mathrm{~m}$ than at $1.0 \mathrm{~m}$-see the column headings in Table 4.)

Visibility of retroreflective traffic signs (Table 5). Vertical aim was, again, the most important factor. The changes in the incident

Table 3 The effects of the selected factors on the visibility of pedestrians and road delineation. The luminous intensities in the column headings are the combined values from the two lamps directed towards the relevant points in space in the baseline condition. The entries are percentage changes in the luminous intensities. (Negative numbers are undesimble changes)

\begin{tabular}{|c|c|c|c|c|}
\hline \multirow[b]{2}{*}{ Factor } & \multicolumn{4}{|c|}{ Pedestrians and delineation } \\
\hline & $\begin{array}{l}\text { Right, } 100 \mathrm{~m} \\
(23428 \mathrm{~cd})\end{array}$ & $\begin{array}{l}\text { Right, } 50 \mathrm{~m} \\
(35959 \mathrm{~cd})\end{array}$ & $\begin{array}{l}\text { Left, } 100 \mathrm{~m} \\
(3864 \mathrm{~cd})\end{array}$ & $\begin{array}{l}\text { Left, } 50 \mathrm{~m} \\
(3731 \mathrm{~cd})\end{array}$ \\
\hline Lamp misaim $1.3^{\circ}$ up & +43 & -15 & +205 & +128 \\
\hline Lamp misaim $1.3^{\circ}$ down & -91 & -86 & -80 & -79 \\
\hline Lamp misaim $1.3^{\circ}$ left & +12 & -14 & +22 & +23 \\
\hline Lamp misaim $0.9^{\circ}$ right & -34 & -8 & -18 & -17 \\
\hline Lamp mounting height $0.58 \mathrm{~m}$ & -4 & -3 & -3 & -8 \\
\hline Lamp mounting height $0.66 \mathrm{~m}$ & +4 & +3 & +3 & +8 \\
\hline Lamp separation $1.36 \mathrm{~m}$ & -1 & -3 & 0 & 0 \\
\hline Lamp separation $0.88 \mathrm{~m}$ & +1 & +2 & 0 & +1 \\
\hline Lamp separation $0 \mathrm{~m}$ & +2 & +6 & 0 & +3 \\
\hline Lens dirt (after $482 \mathrm{~km}$ in winter) & -27 & -27 & -22 & -22 \\
\hline Lamp voltage $12.0 \mathrm{~V}$ & -20 & -20 & -20 & -20 \\
\hline Lamp voltage $13.5 \mathrm{~V}$ & +20 & +20 & +20 & +20 \\
\hline Right lamp only & -55 & -50 & -51 & -57 \\
\hline Left lamp only & -45 & -50 & -49 & -43 \\
\hline light trucks/vans instead of cars & +6 & +10 & -8 & +12 \\
\hline European instead of US pattern & -56 & -42 & -40 & +2 \\
\hline H4 light source instead of $9007^{\circ}$ & -13 & -19 & -31 & -5 \\
\hline
\end{tabular}

The specific luminous intensities listed in the column headings do not apply to these analyses 
Table 4 The effects of the selected factors on the visibility of vehicle reflex reflectors. The luminous intensities in the column headings are the combined values from the two lamps directed towards the relevant points in space in the baseline condition. The entries are percentage changes in the luminous intensities. (Negative numbers are undesirable changes)

\begin{tabular}{lllll}
\hline & \multicolumn{2}{l}{$\begin{array}{l}\text { Right rear reflex reflectors } \\
\text { at } 20 \mathrm{~m} \text {, height of }\end{array}$} & \multicolumn{2}{l}{$\begin{array}{l}\text { Left rear reflex reflectors } \\
\text { at } 20 \mathrm{~m} \text {, height of }\end{array}$} \\
\cline { 2 - 5 } Factor & $0.5 \mathrm{~m}$ & $1.0 \mathrm{~m}$ & $0.5 \mathrm{~m}$ & $1.0 \mathrm{~m}$ \\
& $(18703 \mathrm{~cd})$ & $(1667 \mathrm{~cd})$ & $(8020 \mathrm{~cd})$ & $(862 \mathrm{~cd})$ \\
\hline Lamp misaim $1.3^{\circ}$ up & +69 & +835 & +131 & +670 \\
Lamp misaim $1.3^{\circ}$ down & -88 & -64 & -87 & -44 \\
Lamp misaim $1.3^{\circ}$ left & +13 & +10 & +77 & +23 \\
Lamp misaim $0.9^{\circ}$ right & -10 & -23 & -42 & -14 \\
Lamp mounting height $0.58 \mathrm{~m}$ & -18 & -12 & -18 & -7 \\
Lamp mounting height $0.66 \mathrm{~m}$ & +18 & +15 & +18 & +10 \\
Lamp separation $1.36 \mathrm{~m}$ & -12 & +3 & +21 & +4 \\
Lamp separation $0.88 \mathrm{~m}$ & +14 & -9 & -18 & -5 \\
Lamp separation $0 \mathrm{~m}$ & +40 & -11 & -41 & -10 \\
Lens dirt (after $482 \mathrm{~km}$ in winter) & -27 & -15 & -25 & -2 \\
Lamp voltage $12.0 \mathrm{~V}$ & -20 & -20 & -20 & -20 \\
Lamp voltage $13.5 \mathrm{~V}$ & +20 & +20 & +20 & +20 \\
Right lamp only & -61 & -66 & -77 & -63 \\
Left lamp only & -39 & -34 & -23 & -37 \\
Light trucks/vans instead of cars & +60 & +99 & +95 & +115 \\
European instead of US partern & -60 & -62 & -32 & -43 \\
H4 light source instead of $9007^{a}$ & -23 & -54 & -34 & -54 \\
& & & & \\
\hline
\end{tabular}

The specific luminous intensities listed in the column headings do not apply to these analyses.

Table 5 The effects of the selected factors on the visibility of retroreflective traffic signs and on the visibility of objects near the road exparsion point. The luminous intensities in the column headings are the cormbined values from the two lamps direcred towards the relevant points in space in the baseline condition. The entries are percentage changes in the luminous intensities. (Negative numbers are undesirable changes)

\begin{tabular}{|c|c|c|c|c|}
\hline \multirow[b]{2}{*}{ Factor } & \multicolumn{3}{|c|}{ Retroteflective traffic signs } & \multirow{2}{*}{$\begin{array}{l}\text { Road expansion } \\
\text { point } \\
(5345 \mathrm{~cd})\end{array}$} \\
\hline & $\begin{array}{l}\text { Right, } 150 \mathrm{~m} \\
(5078 \mathrm{~cd})\end{array}$ & $\begin{array}{l}\text { Centre, } 150 \mathrm{~m} \\
(615 \mathrm{~cd})\end{array}$ & $\begin{array}{l}\text { Left, } 150 \mathrm{~m} \\
(1015 \mathrm{~cd})\end{array}$ & \\
\hline Lamp misaim $1.3^{\circ}$ up & +645 & +192 & +487 & +416 \\
\hline Lamp misaim $13^{\circ}$ down & -84 & -31 & -55 & -82 \\
\hline Lamp misaim $1.3^{\circ}$ left & -11 & +1 & +9 & +124 \\
\hline Lamp misaim $0.9^{\circ}$ right & -19 & -3 & -8 & -31 \\
\hline Lamp mounning height $0.58 \mathrm{~m}$ & -2 & 0 & -1 & 0 \\
\hline Lamp mounting height $0.66 \mathrm{~m}$ & +2 & 0 & +1 & 0 \\
\hline Lamp separation $1.36 \mathrm{~m}$ & 0 & 0 & 0 & 0 \\
\hline Lamp separacion $0.88 \mathrm{~m}$ & 0 & 0 & 0 & 0 \\
\hline Lamp separation $0 \mathrm{~m}$ & +1 & 0 & 0 & 0 \\
\hline Lens dirt (after $482 \mathrm{~km}$ in winter) & -24 & +8 & -6 & -24 \\
\hline Lamp roltage $12.0 \mathrm{~V}$ & -20 & -20 & -20 & -20 \\
\hline Lamp voltage $13.5 \mathrm{~V}$ & +20 & +20 & +20 & +20 \\
\hline Right lamp only & -51 & -50 & -50 & -50 \\
\hline Left lamp only & -49 & -50 & -50 & -50 \\
\hline Light trucks/vans instead of cars & -8 & +8 & +4 & -6 \\
\hline European instead of US partern & -82 & -49 & -45 & -77 \\
\hline H4 tight source instead of $9007^{\circ}$ & -43 & -43 & -51 & -51 \\
\hline
\end{tabular}

The specific luminous intensities listed in the column headings do not apply to these analyses.

illumination ranged from $192 \%$ to $645 \%$ (depending on the sign location). The next most important factors were beam pattern (between $45 \%$ and $82 \%$ ) and number of functioning lamps (about 50\%).

Visibility of targets near the road expansion point (Table 5). The greatest effects were for vertical aim (416\%), horizontal aim (124\%) and beam pattern (77\%).

Glare directed towards oncoming drivers (Table 6). The most important factor was vertical aim ( $490 \%)$, followed by number of functioning lamps and light source (both about $50 \%$ ).

Glare reflected from wet pavement towards oncoming drizers (Table 6). The greatest effects were for vertical aim $(53 \%)$, number of functioning lamps (about 50\%) and lens dirt (26\%). Interestingly, however, the wet-road reflected glare illumination is more than 10 times greater than the direct glare illumination (see the column headings in Table 6). Thus, a given percentage change in reflected glare will have more influence on total (reflected plus direct) glare than the same percentage change in direct glare.

Glare directed towards rearview mirrors of preceding vehicles (Table 7). The effects of the strongest factor-vertical aim-ranged from $146 \%$ to $463 \%$. The effects due to vehicle type ranged from $37 \%$ to $91 \%$, while those of number of functioning lamps were around $50 \%$. 
Table 6 The effects of the selected factors on direct glare and reflected glare from wet pavement. The luminous intensities in the column headings are the combined values from the two lamps directed towards the relevant points in space in the baseline condirion. The entries are percentage changes in the luminous intensities. (Positive numbers are undesirable changes)

\begin{tabular}{lcc}
\hline & \multicolumn{2}{c}{ Oncoming driver glare at $50 \mathrm{~m}$} \\
\cline { 2 - 3 } Factor & Direct & Wet pavement \\
& $(990 \mathrm{~cd})$ & $(11340 \mathrm{~cd})$ \\
\hline Lamp misaim $1.3^{\circ}$ up & +490 & -21 \\
Lamp misaim $1.3^{\circ}$ down & -55 & -53 \\
Lamp misaim $1.3^{\circ}$ left & +12 & +16 \\
Lamp misaim $0.9^{\circ}$ right & -8 & -7 \\
Lamp mounting height $0.58 \mathrm{~m}$ & -4 & 0 \\
Lamp mounting height $0.66 \mathrm{~m}$ & +4 & 0 \\
Lamp separation $1.36 \mathrm{~m}$ & 0 & 0 \\
Lamp separation $0.88 \mathrm{~m}$ & 0 & +1 \\
Lamp separation $0 \mathrm{~m}$ & +2 & +3 \\
Lens dirt (after $482 \mathrm{~km}$ in winter) & -5 & -26 \\
Lamp voltage $12.0 \mathrm{~V}$ & -20 & -20 \\
Lamp voltage $13.5 \mathrm{~V}$ & +20 & +20 \\
Right lamp only & -52 & -52 \\
Left lamp only & -48 & -48 \\
Light trucks/vans instead of cars & +34 & 0 \\
European instead of US pattern & -46 & +9 \\
H4 light source instead of $9007^{\circ}$ & -50 & -25 \\
\hline
\end{tabular}

The specific luminous intensities listed in the column headings do not apply to these analyses.

Table 7 The effects of the selected factors on rearview mirror glare. The luminous intensities in the column headings are the combined values from the two lamps directed towards the relevant points in space in the baseline condition. The entries are percentage changes in the luminous intensities. (Positive numbers are undesirable changes)

\begin{tabular}{|c|c|c|c|}
\hline \multirow[b]{2}{*}{ Factor } & \multicolumn{3}{|c|}{ Glare directed towards a rearview mirror at $20 \mathrm{~m}$} \\
\hline & $\begin{array}{l}\text { Left mirror } \\
(2225 \mathrm{~cd})\end{array}$ & $\begin{array}{l}\text { Centre mirror } \\
(699 \mathrm{~cd})\end{array}$ & $\begin{array}{l}\text { Right mirror } \\
(483 \mathrm{~cd})\end{array}$ \\
\hline Lamp misaim $1.3^{\circ}$ up & +146 & +463 & +186 \\
\hline Lamp misain $1.3^{\circ}$ down & -71 & -38 & -33 \\
\hline Lamp misaim $1.3^{\circ}$ left & -12 & +14 & +9 \\
\hline Lamp misaim $0.9^{\circ}$ right & -5 & -13 & -5 \\
\hline Lamp mounting height $0.58 \mathrm{~m}$ & -11 & -7 & -4 \\
\hline Lamp mounting height $0.66 \mathrm{~m}$ & +11 & +7 & +7 \\
\hline Lamp separation $1.36 \mathrm{~m}$ & -2 & -1 & 0 \\
\hline Lamp separation $0.88 \mathrm{~m}$ & +1 & 0 & 0 \\
\hline Lamp separation $0 \mathrm{~m}$ & -2 & +1 & 0 \\
\hline Lens dirt (after $482 \mathrm{~km}$ in winter) & -18 & +4 & +18 \\
\hline Lamp voltage $12.0 \mathrm{~V}$ & -20 & -20 & -20 \\
\hline Lamp voltage $13.5 \mathrm{~V}$ & +20 & +20 & +20 \\
\hline Right lamp only & -45 & -57 & -55 \\
\hline Left lamp only & -55 & -43 & -45 \\
\hline L.ight trucks/vans instead of cars & -37 & +91 & +52 \\
\hline European instead of US pattern & -30 & -49 & -27 \\
\hline H4 light source instead of $9007^{2}$ & +86 & -44 & -10 \\
\hline
\end{tabular}

The specific luminous intensities listed in the column headings do not apply to these analyses.

Foreground illumination (Table 8). None of the effects was over $70 \%$, with the most poten factors being number of functioning lamps, light source and vertical aim.

\subsection{The most important factors}

Table 9 lists, for each performance aspect, the three factors with the greatest effects. Overall, the most potent factor was, by far, vertical aim. It was the factor with the greatest influence on 17 of the 19 performance aspects that were included in Table 9, and it had the second and third greatest effects, respectively, on the remaining two performance aspects. The second most important factor was number of functioning lamps; this factor was the most important factor twice, and it was either the second or the third most important factor 15 times. Other factors represented among the top three factors were beam pattern (featured seven times as either the second or the third most important factor), light source (five times as either the second or the third), vehicle type (five times as either the second or the third), horizontal aim (three times as either the second or the third), and lens dirt (once as the third).

Vertical aim. As indicated above, a criterion of \pm 2 standard deviations (which should be exceeded about $5 \%$ of the time) was used for investigating the effects of factors for which such information was available. These factors included vertical aim, horizontal aim, lamp mounting height and lamp separation. Furthermore, number of functional lamps could be, conceptually, placed into the same category, because the likelihood of one lamp not being funcrional is similar to the likelihood of an event that is two standard deviations or more from the mean. 
Specifically, the most recent estimate is that in the USA the likelihood of one headlamp not being functional is about $2.3 \%(10)$. Furthermore, the lens dirt condition that was included was also rather extreme (after $482 \mathrm{~km}$ in snow and road salt), as were the levels selected for vehicle type (cars versus light trucks and vans), beam pattern (US versus European), and light source (an unshielded 9007 versus a shielded $\mathrm{H} 4$ ). Consequently, a criterion of two standard deviations for vertical misaim appears to be reasonably comparable.

Nevertheless, because vertical aim so dominated all other factors, we also examined the consequences of vertical misaim of only one standard deviation from the mean $\left( \pm 0.65^{\circ}\right)$. Almost a third (32\%) of lamps would exceed this criterion. A comparison of the effects of one and two standard deviations

Table 8 The effects of the selected factors on foreground illumination. The luminous intensities in the column headings are the combined values from the two lamps directed towards the relevant points in space in the baseline condition. The entries are percentage changes in the luminous intensities. (There is not complete consensus whether high levels of foreground illumination are desirable)

\begin{tabular}{lll}
\hline & \multicolumn{2}{l}{ Foreground at } \\
\cline { 2 - 3 } Factor & $15 \mathrm{~m}$ & $25 \mathrm{~m}$ \\
& $(18475 \mathrm{~cd})$ & $(27682 \mathrm{~cd})$ \\
\hline Lamp misaim $1.3^{\circ}$ up & -50 & -40 \\
Lamp misaim $1.3^{\circ}$ down & +45 & -61 \\
Lamp misaim $1.3^{\circ}$ left & +12 & +26 \\
Lamp misain $0.9^{\circ}$ right & -6 & -17 \\
Lamp mounting height $0.58 \mathrm{~m}$ & +10 & +1 \\
Lamp mounting height $0.66 \mathrm{~m}$ & -9 & -1 \\
Lamp separation $1.36 \mathrm{~m}$ & -3 & +2 \\
Lamp separation $0.88 \mathrm{ma}$ & +2 & -2 \\
Lamp separation $0 \mathrm{~m}$ & +7 & -1 \\
Lens dirt (after $482 \mathrm{~km}$ in winter) & -27 & -27 \\
Lamp voltage $12.0 \mathrm{~V}$ & -20 & -20 \\
Lamp voltage $13.5 \mathrm{~V}$ & +20 & +20 \\
Right lamp only & -63 & -70 \\
Left lamp only & -37 & -30 \\
Light trucks/vans instead of cars & +9 & +32 \\
European instead of US pattern & -19 & -22 \\
H4 light source instead of $9007^{\circ}$ & -62 & -44 \\
\hline
\end{tabular}

The specific luminous intensities lissed in the column headings do not apply to these analyses. of vertical misaim are shown in Table 10 , in relation to the effects of the second most important factor, number of functioning lamps. The findings are that even at $\pm 0.65^{\circ}$ of misaim (at one standard deviation) the effects are generally greater than those of the next most important factor.

Number of functioning lamps. As indicated above, the second most influential factor was the number of functioning lamps; this factor was the most important factor twice, and it was either the second or the third most important factor 15 times (see Table 9).

Beam pattern and light source. The light-source manipulation can be considered as a weaker version of the beam-pattern manipulation. The two light sources selected (9007 and H4) create beam patterns that tend to differ along the same lines as do US and European beam patterns. However, both light sources needed to produce beam patterns consistent with current US specifications. The effects of beam pattern and light source are summarised in Table 11. As expected, the US beam pattern and the 9007 light source were superior from the visibility points of view, while the European beam pattern and the $\mathrm{H} 4$ light source were superior from the glare points of view.

Horizontal aim. As expected, horizontal misaim had substantially weaker effects than did vertical misaim. The greatest effects were on the targets near the road expansion point (124\%), followed by left-mounted reflex reflectors at $0.5 \mathrm{~m}$ $(77 \%)$, and pedestrians and delineation (averaging $18 \%$ ).

Lateral separation. The effects of changing the lateral separation from the current mean value of $1.12 \mathrm{~m}$ to either $1.36 \mathrm{~m}$ or $0.88 \mathrm{~m}$ ( \pm 2 standard deviations) were small. (None of the changes was greater than $21 \%$.) Interestingly, assuming a cyclopean position of both lamps (a separation of $0 \mathrm{~m}$ ) also had only small effects (11\% or less), with one exception. Specifically, for both the right and left vehicle reflex reflectors mounted at $0.5 \mathrm{~m}$ (near the mounting height of the lamps), using a cyclopean position reduced the incident illumination by about $40 \%$. Overall, the present analyses indicate that using a cyclopean approximation to lamp separation does not introduce major errors, except when the target in question is both at a near distance and at a mounting height near that of the headlamps.

Table 9 Rank ordering of the factors by the size of the effects on the performance aspects

\begin{tabular}{|c|c|c|c|}
\hline \multirow[b]{2}{*}{ Performance aspect } & \multicolumn{3}{|c|}{ Rank ordering of factors by the size of the effect } \\
\hline & First & Second & Third \\
\hline Visibility of a right pedestrian and road delineation at $100 \mathrm{~m}$ & Vertical aim & Beam pattern & One lamp only \\
\hline Visibility of a right pedestrian and road delineation at $50 \mathrm{~m}$ & Vertical aim & One lamp only & Beam pattern \\
\hline Visibility of a left pedestrian and road delineation at $100 \mathrm{~m}$ & Vertical aim & One lamp only & Beam pantern \\
\hline Visibility of a left pedestrian and road delineation ar $50 \mathrm{~m}$ & Vertical aim & One lamp only & Horizontal aim \\
\hline Visibility of a right rear reflem reflector at $20 \mathrm{~m}$; mounting height $0.5 \mathrm{~m}$ & Vertical aim & One lamp only & Bearn pattern \\
\hline Visibility of a right sear reflex reflector at $20 \mathrm{~m}$; mounting height $1.0 \mathrm{~m}$ & Vertical aim & Vehicle type & One lamp only \\
\hline Visibility of a left rear reflex reflector at $20 \mathrm{~m}$; mounting height $0.5 \mathrm{~m}$ & Vertical aim & Vehicle type & Horizontal aim \\
\hline Visibility of a left rear reflex reflector at $20 \mathrm{~m}$; mounting height $1.0 \mathrm{~m}$ & Vertical aim & Vehicle type & One lamp only \\
\hline Visibility of a retroreflective traffic sign; right shoulder at $150 \mathrm{~m}$ & Vertical aim & Beam pattern & One lamp only \\
\hline Visibility of a retroreflective traffic sign; centre overhead at $150 \mathrm{~m}$ & Vertical aim & One lamp only & Bearn partern \\
\hline Visibility of a retroreflective traffic sign; left shoulder at $150 \mathrm{~m}$ & Vertical aim & Light source & One lamp only \\
\hline Visibility of a target near the road expansion point & Vertical aim & Horizontal aim & Beara partern \\
\hline Glare directed towards an oncoming driver at $50 \mathrm{~m}$ & Vertical aim & One lamp only & Light source \\
\hline Glare reflected from wet pavement towards an oncoming driver at $50 \mathrm{~m}$ & Vertical aim & One lamp only & Lens dirt \\
\hline Glare direcred towards a left mirror in the right adjacent lane at $20 \mathrm{~m}$ & Vertical aim & Light source & One lamp only \\
\hline Glare directed towards a centre mirror in the same lane at $20 \mathrm{~m}$ & Vertical aim & Vehicle type & One lamp only \\
\hline Glare directed towards a right mirror in the left adjacent lane at $20 \mathrm{~m}$ & Vertical ain & One lamp only & Vehicle type \\
\hline Foreground illumination at $15 \mathrm{~m}$ & One lamp only & Light source & Vertical aim \\
\hline Foreground illumination at $25 \mathrm{~m}$ & One lamp only & Vertical aim & Light source \\
\hline
\end{tabular}




\section{Sivak et al.}

Table 10 The effects of vertical misaim of $\pm 1.30^{\circ}$ and $\pm 0.65^{\circ}$, compared with the effects of number of functioning lamps. The entries are percentage changes in the luminous intensities

\begin{tabular}{|c|c|c|c|}
\hline \multirow[b]{2}{*}{ Performance aspect } & \multicolumn{2}{|c|}{ Vertical misaim } & \multirow{2}{*}{$\begin{array}{l}\text { One lamp only } \\
\text { Right } \\
\text { (Left) }\end{array}$} \\
\hline & $\begin{array}{l}\text { Up } 1.3^{\circ} \\
\left.\text { (Up } 0.65^{\circ}\right)\end{array}$ & $\begin{array}{l}\text { Down } 1.3^{\circ} \\
\text { (Down 0.65) }\end{array}$ & \\
\hline Visibility of a right pedestrian and road delineation at $100 \mathrm{~m}$ & $+43(+56)$ & $-91(-70)$ & $-55(-45)$ \\
\hline Visibility of a right pedestrian and road delineation at $50 \mathrm{~m}$ & $-15(+12)$ & $-86(-53)$ & $-50(-50)$ \\
\hline Visibility of a left pedestrian and road delineation at $100 \mathrm{~m}$ & $+205(+122)$ & $-80(-60)$ & $-51(-49)$ \\
\hline Visibility of a left pedestrian and road delineation at $50 \mathrm{~m}$ & $+128(+89)$ & $-79(-60)$ & $-57(-43)$ \\
\hline Visibility of a right rear reflex reflector at $20 \mathrm{~m}$; mounting height $0.5 \mathrm{~m}$ & $+69(+65)$ & $-88(-67)$ & $-61(-39)$ \\
\hline Visibility of a right rear reflex reflector at $20 \mathrm{~m}$; mounting height $1.0 \mathrm{~m}$ & $+835(+191)$ & $-64(-50)$ & $-66(-34)$ \\
\hline Visibility of a left rear reflex reflector at $20 \mathrm{~m}$; mounting height $0.5 \mathrm{~m}$ & $+131(+101)$ & $-87(-68)$ & $-77(-23)$ \\
\hline Visibility of a left rear reflex reflector at $20 \mathrm{~m}$; mounting height $1.0 \mathrm{~m}$ & $+670(+139)$ & $-44(-31)$ & $-63(-37)$ \\
\hline Visibility of a retroreflecrive traffic sign; right shoulder at $150 \mathrm{~m}$ & $+645(+244)$ & $-84(-71)$ & $-51(-49)$ \\
\hline Visibility of a retroreflective traffic sign; centre overhead at $150 \mathrm{~m}$ & $+192(+40)$ & $-31(-16)$ & $-50(-50)$ \\
\hline Visibility of a retroreflective traftic sign; left shouider at $150 \mathrm{~m}$ & $+487(\div 140)$ & $-55(-42)$ & $-50(-50)$ \\
\hline Visibility of a target near the road expansion point & $+416(+278)$ & $-82(-61)$ & $-50(-50)$ \\
\hline Glare directed towards an oncoming driver at $50 \mathrm{~m}$ & $+490(+142)$ & $-55(-41)$ & $-52(-48)$ \\
\hline Glare reflected from wet pavement towards an oncoming driver at $50 \mathrm{~m}$ & $-21(-7)$ & $-53(-12)$ & $-52(-48)$ \\
\hline Glare directed towards a left mirror in the right adjacent lane at $20 \mathrm{~m}$ & $+146(+61)$ & $-71(-53)$ & $-45(-55)$ \\
\hline Glare directed towards a centre mirror in the same lane at $20 \mathrm{~m}$ & $+463(+84)$ & $-38(-25)$ & $-57(-43)$ \\
\hline Glare directed towards a right mirror in the left adjacent lane at $20 \mathrm{~m}$ & $+186(+55)$ & $-33(-22)$ & $-55(-45)$ \\
\hline Foreground illumination at $15 \mathrm{~m}$ & $-50(-27)$ & $+45(+39)$ & $-63(-37)$ \\
\hline Foreground illumination at $25 \mathrm{~m}$ & $-40(-19)$ & $-61(-14)$ & $-70(-30)$ \\
\hline
\end{tabular}

Table 11 The effects of beam pattern and light source. The entries are percentage changes in the luminous intensities. The changes in the desirable directions are in parentheses

\begin{tabular}{|c|c|c|}
\hline Performance aspect & $\begin{array}{l}\text { Beam pattern } \\
\text { (European instead } \\
\text { of US) }\end{array}$ & $\begin{array}{l}\text { Light source } \\
\text { (H4 instead } \\
\text { of } 9007 \text { ) }\end{array}$ \\
\hline Visibility of a right pedestrian and road delineation at $100 \mathrm{~m}$ & -56 & -13 \\
\hline Visibility of a righr pedestrian and road delineation at $50 \mathrm{~m}$ & -42 & -19 \\
\hline Visibility of a left pedestrian and road deineation at $100 \mathrm{~m}$ & -40 & -31 \\
\hline Visibility of a left pedestrian and road delineation at $50 \mathrm{~m}$ & $(+2)$ & -5 \\
\hline Visibility of a right rear reflex reflector at $20 \mathrm{~m}$; mounting height $0.5 \mathrm{~m}$ & -60 & -23 \\
\hline Visibility of a right rear reflex reflector at $20 \mathrm{~m}$; mounting height $1.0 \mathrm{~m}$ & -62 & -54 \\
\hline Visibility of a left rear reflex reflector at $20 \mathrm{~m}$; mounting height $0.5 \mathrm{~m}$ & -32 & -34 \\
\hline Visibility of a left rear reflex reflector at $20 \mathrm{~m}$; mounting height $1.0 \mathrm{~m}$ & -43 & -54 \\
\hline Visibility of a retroreflective traffic sign; right shoulder at $150 \mathrm{~m}$ & -82 & -43 \\
\hline Visibility of a retroreflective traffic sign; centre overhead at $150 \mathrm{~m}$ & -49 & -43 \\
\hline Visibility of a retroreflective traffic sign; left shoulder at $150 \mathrm{~m}$ & -45 & -51 \\
\hline Visibility of a target near the road expansion point & -77 & -53 \\
\hline Glare direcred rowards an oncoming driver at $50 \mathrm{~m}$ & $(-46)$ & $(-50)$ \\
\hline Glare reflected from wet pavement towards an oncoming diviver at $50 \mathrm{~m}$ & +9 & $(-26)$ \\
\hline Glare directed towards a left mirror in the right adjacent lane at $20 \mathrm{~m}$ & $(-30)$ & +86 \\
\hline Glare directed towards a centre mirror in the same lane at $20 \mathrm{~m}$ & $(-49)$ & $(-44)$ \\
\hline Glare directed towards a right mirror in the left adjacent lane at $20 \mathrm{~m}$ & $(-27)$ & $(-10)$ \\
\hline Foreground illumination at $15 \mathrm{~m}$ & -19 & $-62^{a}$ \\
\hline Foreground illumination at $25 \mathrm{~m}$ & $-22^{a}$ & $-44^{a}$ \\
\hline
\end{tabular}

There is not complete consensus about whether high leveds of foreground illumination are desirable or undesirable.

Mounting height. The effects of changing the lamp mounting height from the current mean value of $0.62 \mathrm{~m}$ to either $0.66 \mathrm{~m}$ or $0.58 \mathrm{~m}( \pm 2$ standard deviations) ranged from negligible to small ( $18 \%$ or less). The greatest effects were on vehicle reflex reflectors and rearview mirror glare.

Vehicle type. This manipulation was primarily a more extreme manipulation of mounting height (from $0.62 \mathrm{~m}$ to $0.83 \mathrm{~m}$ ), coupled with a modest beam-pattern change. The effects ranged from negligible (averaging $8 \%$ for traffic signs) to major (averaging $92 \%$ for vehicle reflex reflectors).

Lens dirt. The effects of dirt were generally moderate, with a maximum of $27 \%$.
Lamp voltage. The values investigated $(12.0 \mathrm{~V}$ and $13.5 \mathrm{~V})$ result in $20 \%$ changes in luminous intensity (down and up, respectively) for all performance aspects.

\subsection{Relative versus absolute effects}

The primary focus of this study was on the relative effects of a variety of factors. However, the present data can also be used for making inferences about the absolute effects of these factors. For this, we recommend as a reasonable criterion the magnitude of the effects due to one lamp not being functional. According to this recommendation, any effects that exceed this criterion (near $50 \%$ for all performance functions) should be considered substantial. 


\section{Conclusions}

This study compared the quantitative influence of a variety of factors on the performance of low-beam headlamps. The goal was to derive a rank ordering of the importance of these factors for improving low-beam headlighting.

The following factors were included: vertical aim, horizontal aim, mounting height, lateral separation (including a comparison of two lamps located in the same position versus lamps laterally separated), lens dirt, lamp voltage, number of functioning lamps (two versus one), vehicle type (cars versus light trucks and vans), beam pattern (US versus European), and light source (an unshielded 9007 versus a shielded H4). Whenever the information on the distribution of the factors was available, a range of \pm 2 standard deviations was used in the calculations.

The following performance aspects were considered: visibility of pedestrians, visibility of road delineation, visibility of vehicle reflex reflectors, visibility of retroreflective traffic signs, visibility of targets near the road expansion point, glare directed towards oncoming drivers, glare reflected from wet pavement towards oncoming drivers, glare directed towards rearview mirrors of preceding vehicles, and foreground illumination. A sales-weighted average US beam pattern, with lamps mounted at sales-weighted average locations, formed the basis for most of the analyses.

For each of the performance aspects, typical geometric situations (points in space) were specified in terms of the longitudinal, lateral and vertical positions, and the corresponding visual angles from each of the two lamps were calculated. The effects of the factors were quantified by calculating the percentage change in luminous intensity directed from both lamps towards the points in space representing the performance aspects.

The results indicate that, from among the factors studied, vertical aim is overwhelmingly the most important factor in influencing the performance of low-beam headlamps. The second most important factor was the number of functioning lamps.

The main implication of this study is that major improvements in current (fixed as opposed to adaptive) low-beam headlighting could be achieved primarily by better control of vertical aim, and by use of longer-life headlamps. Longer life could be provided by either high-intensity discharge or longer-life incandescent sources. (Longer life for incandescents results in decreased efficacy, which should not be allowed to be expressed as a loss of light output.)

\section{Acknowledgements}

Appreciation is extended to the members of the University of Michigan Industry Affiliation Program for Human Factors in Transportation Safety for support of this research. The current members of the program are Adac Plastics, AGC America, Automotive Lighting, BMW, Britax International, Corning, DaimlerChrysler, Denso, Donnelly, Federal-Mogul Lighting Products, Fiat, Ford, GE, GM NAO Safety Center, Guardian Industries, Guide Corporation, Hella, Ichikoh Industries, Koito Manufacturing, LESCOA, Libbey-Owens-Ford, LumiLeds, Magna International, North American Lighting, OSRAM Sylvania, Philips Lighting, PPG Industries, Reflexite, Reitter \& Schefenacker, Stanley Electric, Stimsonite, TEXTRON Automotive, Valeo, Visteon, Yorka, 3 M Personal Safety Products and 3M Traffic Control Materials.

An abbreviated version of this paper was presented at the $3 \mathrm{rd}$ Symposium on Progress in Automotive Lighting, Darmstadt, Germany, September 1999.

\section{References}

1 Bhise V D, Matle C C and Hoffmeister D H CHEss model applications in headlamp systems eahuation SAE Technical Paper Series 840046 (Warrendale PA: Society of Automotive Engineers) (1984)

2 Sivak $M$, Flannagan $M$ J, Traube E C, Kojima $S$ and Aoki $M$ Lowbeam headlamps: effects of realistic dirt levels on light outpur Lighting Res. Technol. 29 15-22 (1997)

3 Perel M, Evaluation of headlamp beam patterns using the Ford ChEss program Proceedings of the Tenth International Technical Conference on Experimental Safety Vehicles pp 225-229 (Washington DC: US Department of Transportation) (1985)

4 Bhise V D, Farber E I, Saunby C S, Troell G M, Walunas I B and Bernstein A Modeling vision with headlights in a systems context SAE Technical Paper Series 770238 (Warrendale PA: Society of Automotive Engineers) (1977)

5 Sivak M, Flannagan M J, Kojima $S$ and Traube E C A market-weighted description of low-beam headlighting patterns in the US SAE Technical Report Series 980317 (Warrendale PA: Society of Automotive Engineers) (1998)

6 Sivak M, Flannagan M J, Budnik E, Flannagan C and Kojima S The locations of headlamps and driver eye positions in vehicles sold in the US Ergonomics $40872-878$

7 Sivak $M$, Flannagan $M$ J, Traube $\mathrm{E} C$ and Miyokawa $\mathrm{T}$ Do changes in voltage result in proporional changes throughout headlamp beam patterns? Lighting Res. Technol. 31 1-3 (1999)

8 Copenhaver M M and Jones E Measurement of headlamp cim and the electrical and photometric perfornuance characteristics of rear lighting systems Report No. DOT HS 807930 (Washington DC: US Department of Transportation) (1992)

9 Lighting handbook: reference and application 8th edn (New York: Illuminating Engineering Society of North America) (1993)

10 Rys $M, K o n z S$ and Russell $E$ Headlight ourages Presented at the $S A E$ Congress, Detrit (1993)

11 Sivak M, Flannagan $M J$ and Sato $T$ Light output of US, European and Japanese low-bearo headlamps Transponotion Res. Rec. 1456 99-111 